\title{
Ectopic ACTH-producing lung cancer presenting with prostatic metastasis
}

\author{
H. M. SMEDLEY* \\ M.B., B.S., F.R.C.R.
}

\author{
C. BROWN $\dagger$ \\ M.R.C.P., F.R.C.R.
}

\begin{abstract}
A. TURNER $\ddagger$
B.Sc., F.R.C.S.

${ }^{*}$ Ludwig Institute for Cancer Research, Cambridge, and Huntingdon Oncology Clinic, Hinchingbrooke Hospital, Huntingdon, †Department of Radiotherapy, Addenbrooke’s Hospital, Cambridge and $\ddagger$ Department of Urology, Peterborough General Hospital
\end{abstract}

\section{Summary}

The case is described of a patient presenting with prostatic symptoms and a biopsy proven neoplasm in the prostate gland. Radical radiotherapy initially given to the pelvis produced satisfactory symptomatic improvement with tumour regression, but the patient subsequently developed endocrine complications which led to the site of the primary carcinoma being reconsidered. The case illustrates the ubiquitous nature of aggressive metastatic cancer.

KEY WORDS: lung carcinoma, prostatic metastases, ACTH.

\section{Case report}

A 48-year-old carpenter presented with a 6 month history of dysuria and hesitancy. There was no other history and no relevant past history. Examination of the abdomen showed no abnormality but rectal examination revealed a large hard prostate. An examination under anaesthetic and cytoscopy confirmed a large hard prostate with extension to the left lateral side wall, clinically stage T4. A needle biopsy was obtained and this was reported as undifferentiated carcinoma. Further staging investigations, including intravenous urogram, bone scan and chest $X$ ray were performed and showed no evidence of dissemination beyond the pelvis. The patient was therefore considered to have a locally invasive carcinoma of the prostate with no evidence of dissemination (T4 $\mathrm{N} \times \mathrm{Mo}$ ). During the time he was undergoing these investigations, he developed bilateral leg oedema, which was considered to be due to lymphatic obstruction in the pelvis. In line with the general policy of this department, he was referred for prostatic radiotherapy and received radical radiation to the whole pelvis as an outpatient. During the course of his treatment, the patient's prostatic symp- toms improved considerably and his leg oedema resolved.

Three weeks following the completion of radiotherapy, the patient re-presented with recurrence of his ankle oedema but was otherwise well at this time, and was treated with oral diuretics. Despite this, he continued to deteriorate and soon had generalised oedema associated with some leg weakness. Further investigation was instituted, including a computed tomographic scan of the abdomen, which showed multiple liver metastases and enlarged peritoneal and para-aortic glands. The patient was also found to have hypokalaemia (potassium $2.2 \mathrm{mmol} /$ litre; sodium $145 \mathrm{mmol} /$ litre; urea $3.3 \mathrm{mmol} / \mathrm{litre}$; bicarbonate $41.1 \mathrm{mmol} /$ litre). The clinical picture became increasingly that of Cushing's syndrome (plasma cortisol level $>1,750 \mathrm{nmol} /$ litre with no diurnal variation). Because both Cushing's syndrome and liver metastases are rare with carcinoma of the prostate, further tissue for histological examination was sought. A needle liver biopsy was reported as containing a small cell carcinoma, suggestive of disseminated oat cell carcinoma of the lung. About this time, the patient's general condition deteriorated and, despite aggressive medical treatment of the Cushing's syndrome, he rapidly deteriorated and died $2 \frac{1}{2}$ months after his initial presentation. Autopsy was performed at which microscopic evidence of disseminated oat cell carcinoma was discovered throughout the lungs, but the site of the primary tumour was not found.

\section{Discussion}

Small cell carcinoma of the lung is an aggressive tumour which frequently metastasises and may well present with complications of the metastases. Metastasis to the prostate is uncommon (Willis, 1973) and 
has not previously been reported as the sole site of disease at the time of presentation. Despite the welldefined patterns of metastases associated with most tumours commonly encountered in the clinic, this patient demonstrates that any primary tumour can metastasise to any part of the body and may present with complications arising from that metastasis. This feature of malignant disease must be especially considered in patients with histological evidence of undifferentiated carcinoma before the institution of what may well be inappropriate radical therapy.

\section{Acknowledgment}

We are grateful to Dr K. Sikora for helpful discussion. Reference

WILLIS, R.A. (1973) In: Spread of Tumours in the Human Body, p.c. 285. Butterworth, London.

(Accepted 30 September 1982) 